\title{
Commentary: A lethal disease begging for treatment consensus
}

\author{
Jennifer S. Lawton, MD
}

\author{
From the Division of Cardiac Surgery, Department of Surgery, Johns Hopkins University, Baltimore, Md. \\ Disclosures: Author has nothing to disclose with regard to commercial support. \\ Received for publication Feb 15, 2019; accepted for publication Feb 18, 2019; available ahead of print March 23 , \\ 2019. \\ Address for reprints: Jennifer S. Lawton, MD, Johns Hopkins Hospital, 1800 Orleans St, Zayed 7107, Baltimore, \\ MD 21287 (E-mail: jlawton4@jhmi.edu). \\ J Thorac Cardiovasc Surg 2019;158:1525-6 \\ $0022-5223 / \$ 36.00$ \\ Copyright (c) 2019 by The American Association for Thoracic Surgery \\ https://doi.org/10.1016/j.jtcvs.2019.02.073
}

In this issue of the Journal, Leshnower and associates ${ }^{1}$ presents results in 34 patients with acute type A aortic dissection with mesenteric malperfusion during a 14-year period. They originally proposed an approach of thoracic endovascular aortic repair (TEVAR)-first repair in 2014 in an attempt "to improve the dismal outcomes associated with this malperfusion syndrome" and stated that the goal of this paradigm was to expand the true lumen mechanically and increase inflow into the distal aorta. ${ }^{2}$ Their current summary ${ }^{1}$ again supports a TEVAR-first approach for these patients with a known risk of high mortality $(55.8 \%$ in this series) and $100 \%$ mortality when associated with severe acidosis. ${ }^{3}$ This paradigm involves TEVAR followed by ascending aortic replacement after a variable delay. This innovative approach addresses a need to improve operative mortality and outcomes with this lethal disease.

Similar to other published experiences of treatment of type A aortic dissection, the patients are a diverse group with a variety of surgical treatments, including ascending aorta with or without arch followed by laparotomy, axillary-bifemoral bypass followed by ascending aorta with or without arch replacement, ascending aorta with or without arch replacement with antegrade TEVAR, and TEVAR-first approach followed by delayed ascending aorta with or without arch replacement. Treatment was based on surgeon preference and varied with time. Because there are multiple technical steps that must be orchestrated in the surgical treatment of an acute type A aortic dissection (Table 1), and these operations are often performed at late hours or on weekends (because of delay in diagnosis or transfer between hospitals), a standardized approach seems reasonable, safe, and appropriate.

The patients in the TEVAR-first group were in stable condition at the time of presentation, and contraindications to this strategy included hemodynamic instability, cardiac tamponade, respiratory compromise,

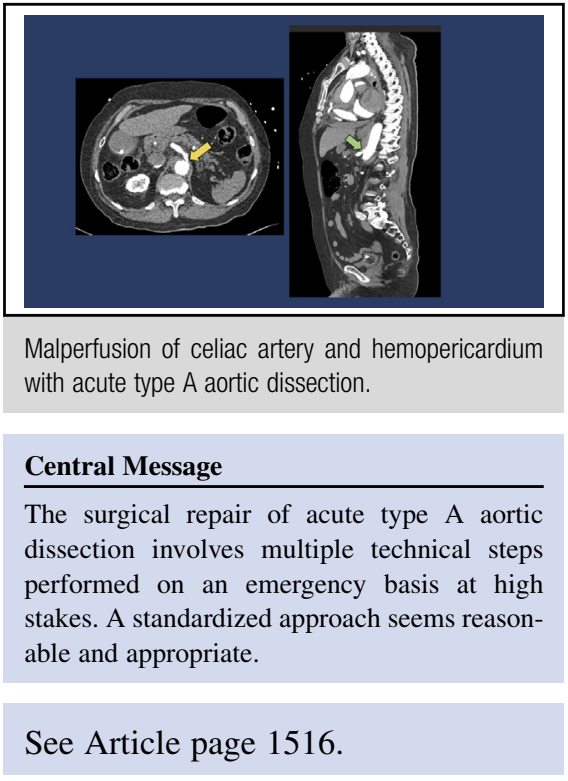

hemopericardium, intractable chest pain, evolving stroke, coronary malperfusion, and severe aortic insufficiency. These exclusion criteria are precisely the reasons that aortic surgery is typically not delayed, because $50 \%$ of patients die within the first 48 hours. ${ }^{4}$ The TEVAR-first group was thus in more stable condition on presentation and (except for 1 patient who died waiting) were likely selected to survive, introducing inherent bias. Leshnower and associates ${ }^{1}$ suggest that delay in ascending aorta replacement in the TEVAR-first group as a bridge to decision tool is justified. This may save the resources needed for aortic replacement and postoperative care; however, information such as the time from symptom onset and lactate levels could also inform decisions. The mortality of this group was 30\% (3/10); however, 3 patients did not survive until ascending aortic repair, making the actual mortality $46 \%$ (6/13), which was not significantly different from the other groups, given the small number in each.

Leshnower and associates ${ }^{1}$ recommend axillarybifemoral bypass followed by ascending replacement for patients in unstable condition. They note that this provides antegrade and retrograde flow in the aorta (and presumably to the abdominal viscera through a false lumen that may be dynamic). One might argue, why not just cannulate the femoral artery for bypass and expeditiously perform ascending replacement with deep hypothermic circulatory 
TABLE 1. Multiple potential technical steps in emergency surgery for acute type A aortic dissection repair

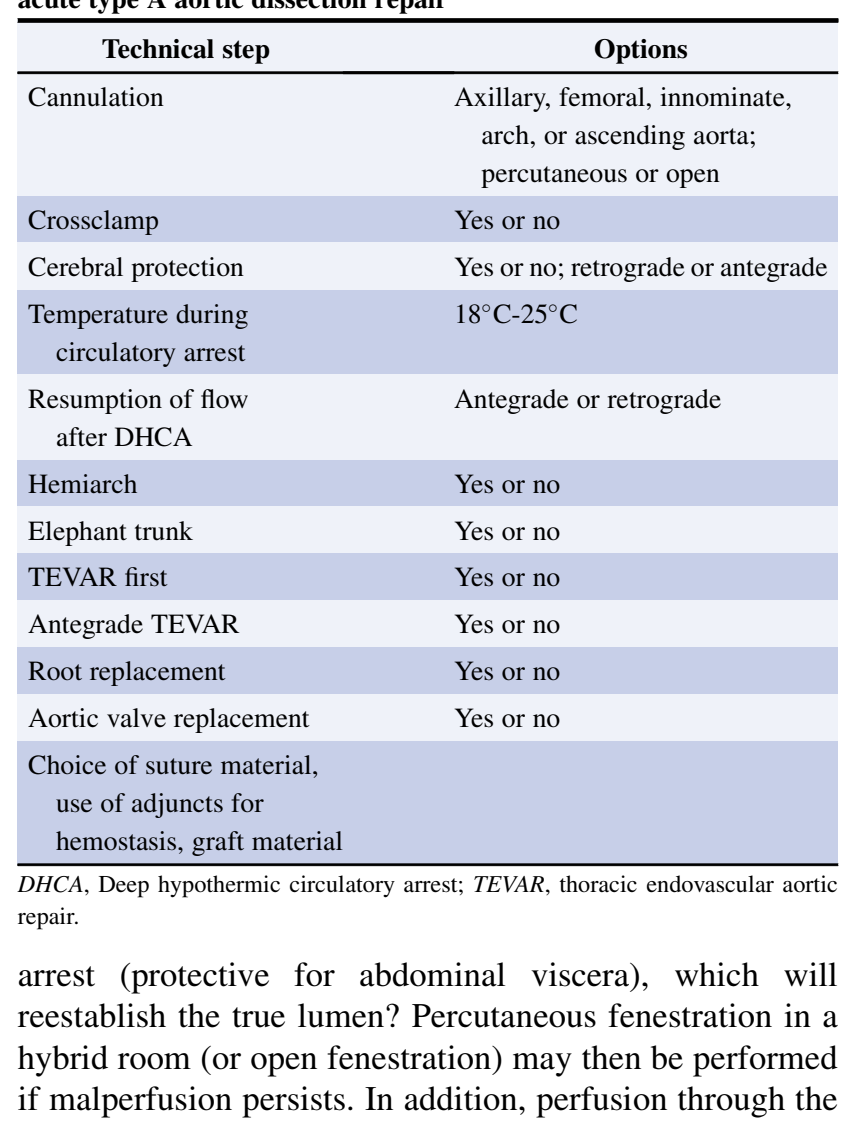

native aorta and the axillary-bifemoral route after cardiopulmonary bypass, as proposed by Leshnower and associates, ${ }^{1}$ may introduce more intimal reentry tears as suggested by David. ${ }^{5}$

No standardization exists, and there are no guidelines regarding many of the technical steps of surgical repair of acute type A aortic dissection. A safe approach for any cardiac surgeon to get the patient out of the operating room alive has been described. ${ }^{6}$ Many questions regarding the best care for these patients are again raised by the current series of Leshnower and associates, ${ }^{1}$ and they will remain unanswered without a randomized trial.

\section{References}

1. Leshnower BG, Keeling WB, Duwayri YM, Jordan WD Jr, Chen EP. The "thoracic endovascular aortic repair-first" strategy for acute type A dissection with mesenteric malperfusion: initial results compared with conventional algorithms. J Thorac Cardiovasc Surg. 2019;158:1516-24.

2. Leshnower BG, Veeraswamy RK, Duwayri YM, Chen EP. The "TEVAR-first" approach to DeBakey I aortic dissection with mesenteric malperfusion. Ann Thorac Surg. 2014;97:693-6.

3. Lawton JS, Moon MR, Liu J, Koerner DJ, Kulshrestha K, Damiano RJ Jr, et al. The profound impact of combined severe acidosis and malperfusion on operative mortality in the surgical treatment of type A aortic dissection. J Thorac Cardiovasc Surg. 2018;155:897-904.

4. Mehta RH, Suzuki T, Hagan PG, Bossone E, Gilon D, Llovet A, et al; International Registry of Acute Aortic Dissection (IRAD) Investigators. Predicting death in patients with acute type A aortic dissection. Circulation. 2002;105:200-6.

5. David TE, Armstrong S, Ivanov J, Barnard S. Surgery for acute type A aortic dissection. Ann Thorac Surg. 1999;67:1999-2001; discussion 2014-9.

6. David TE. Surgery for acute type A aortic dissection. J Thorac Cardiovasc Surg. 2015;150:279-83. 